\title{
Effects of Hydrocarbons on Wind Waves in a Mine Pit Lake
}

\author{
David Hurley $^{1}\left[\right.$. Gregory Lawrence ${ }^{1} \cdot$ Edmund Tedford $^{1}$
}

Received: 29 January 2019 / Accepted: 24 April 2020 / Published online: 20 May 2020

(c) The Author(s) 2020

\begin{abstract}
The extraction and upgrading of bitumen to crude oil from the Canadian oil sands has produced large quantities of byproducts such as fluid fine tailings (FFT) and oil sands process affected water (OSPW). One reclamation strategy for these byproducts is to backfill a mined-out pit with FFT and cap it with a mix of OSPW and non-process affected water to form a pit lake. We investigated the effects of hydrocarbons, residual bitumen, on the generation and growth of wind waves, both in the laboratory and in a pit lake. In the laboratory, we compared the wind wave characteristics in the presence and absence of a hydrocarbon film. We showed that the hydrocarbon film dampens high frequency waves, resulting in a slower growing wave field dominated by lower frequency waves. These results were consistent with our field observations. Thus, it appears that the presence of a hydrocarbon film on a pit lake leads to a wind wave field dominated by longer wavelength waves that take more time to develop and grow at a slower rate. This is important since wind wave-driven mixing, in tandem with biogeochemical processes, governs water quality in mine pit lakes. Thus, this work improves understanding of the physical processes that effect water quality in mine pit lakes and enhances the ability of mine managers to conduct pit lake reclamation.
\end{abstract}

Keywords End pit lakes $\cdot$ Oil sands $\cdot$ Physical limnology $\cdot$ Mine water $\cdot$ Tailings ponds

\section{Introduction}

A leading challenge in the oil sands industry is the storage and reclamation of bitumen extraction byproducts such as fluid fine tailings (FFT) and oil sands process affected water (OSPW). One potential reclamation strategy is to turn a mined-out pit into a mine pit lake, called an end pit lake, by backfilling the pit with FFT and capping it with OSPW (Lawrence et al. 2015). In 2013, Base Mine Lake (BML) became the first full scale demonstration end pit lake in the oil sands industry. One concern was the presence of hydrocarbons, residual bitumen from the extraction process, on the lake's surface and their effect on wind waves. It has been observed that in the presence of hydrocarbons, there is a reduction in surface ripples and a general dampening of the wind wave field. These changes in the wind wave field due to a hydrocarbon sheen may have several important environmental consequences.

David Hurley

david_hurley@golder.com

1 Department of Civil Engineering, University of British Columbia, Vancouver, BC V6T 1W5, Canada
A dampening of the wind wave field caused by a reduction in wind energy, as might occur in the presence of a hydrocarbon sheen, reduces the amount of physical mixing in the water cap. Arriaga et al. (2019) noted that the balance between physical mixing and biogeochemical processes in BML controls the distribution of dissolved oxygen throughout the water cap and "underpins the likely viability of this reclamation strategy for oil sands FFT". Additionally, the water cap in many mine pit lakes and tailings ponds is saline due to chemicals used in the extraction process, but a freshwater layer forms on the surface in colder climates when ice melts. Pieters and Lawrence (2009) observed that spring winds may not be powerful enough to mix this freshwater layer, resulting in a suppression or delay of water cap turnover (i.e. spring turnover). Turnover suppression can have devastating effects on water quality, such as not replenishing dissolved oxygen consumed during the ice-cover season. Therefore, a reduction in wind energy at the pit lake surface as a result of a hydrocarbon sheen will increase the likelihood of turnover suppression.

Most mine pit lakes and tailings ponds are shallow enough that the near-bed orbital motions associated with wind waves are strong enough to resuspend bottom sediments and increase the suspended sediment concentration 
in the water cap (Lawrence et al. 1991). Mian and Yanful (2003) investigated resuspension of sulfide-bearing tailings and concluded that reducing resuspension would reduce oxidization of the tailings and lead to a decreased concentration of contaminants in the water cap. Although BML was designed so the water cap would be sufficiently deep to stratify and not be susceptible to direct resuspension by near-bed orbital motions associated with wind-waves, there are still several indirect wind wave induced mechanisms that might increase the suspended sediment concentration and turbidity in the water cap (Lawrence et al. 2015; Tedford et al. 2019). Any increase in turbidity will reduce the photic depth and may alter biological activity within the water cap.

While a variety of laboratory studies have been conducted to examine the calming effect of oil on wind waves (Broecker et al. 1978; Liu and Lin 1979), few field studies have been performed. In this study, we examined the effect of oil on wind waves both in the laboratory and the field. First, a brief review of the effect of oil on waves is given, then the generation of wind waves on clean and oil-contaminated surfaces is described, followed by the laboratory and field methods. The results of the laboratory and field experiments are then reviewed, and the implications of a modified wind wave field on physical processes in BML are discussed.

\section{Background}

Since ancient times people have been fascinated with the effects of oil on wind waves. Records from the 1st millennium $\mathrm{AD}$ describe ships pouring oil on rough seas to calm the waves, and over the next 800 years, tales of the calming effect of oil on water appear sporadically (Fulford 1968). Then, Franklin et al. (1774) published "Of the Stilling of Waves by Means of Oil," which drew simple yet important conclusions from numerous experiments, the most famous carried out at a pond in the Clapham district of South London. Franklin, adding only a teaspoon of oil on the windward side of the pond, observed a patch of water, roughly an acre in size, become still as glass in a short period of time. From this and other experiments, Franklin concluded that oil prevents the formation of new waves, and reduces the presence of small waves and whitecaps within a swell, but does not affect the height of large waves.

During the next century, the calming effect of oil on water attracted not only scientific, but commercial interest. Politicians in Britain lobbied for ships to carry tanks of oil for discharge in rough weather, and the US Life-Saving Service (the precursor to the US Coast Guard) looked into the use of oil during rescues (Giles 1969; Sparrow 1883). On the scientific side, Aitken (1884) ascertained through laboratory experiments that it was the reduction in surface tension that diminished the number of ripples. Then, Pockels (1891) found that while reduction of surface tension plays a role in wave damping, it could not be the entire cause. This work ultimately led Reynolds to postulate that gradients in surface tension are key to the damping effect of oil on wind waves (Giles 1969; Reynolds 1880).

When a wind blows above a critical speed over an undisturbed water surface, small ripples, known as capillary waves, are the first to form (Kinsman 1984). These waves generally have wavelengths less than a few centimeters and surface tension is the dominant restoring force. As long as the wind continues to blow, and the energy input from the wind is greater than the rate of energy dissipation, the capillary waves will grow larger. Once the capillary waves reach a wavelength of $\approx 1 \mathrm{~cm}$, they begin to experience the restoring forces of gravity as well as surface tension. Eventually, when the wavelength exceeds $\approx 3 \mathrm{~cm}$, the gravity effects dominate, and the waves continue to increase in both length and amplitude, until there is a balance between energy input from the wind and energy dissipated. At this point, the wind wave field is fully developed and, while the largest waves cease to grow, new capillary waves form on the wave faces and start the process anew. This fully developed sea state consists of capillary, gravity-capillary, and gravity waves all with different wavelengths and travelling at different wave speeds. The wave speed, $c=\omega / k$, and wavelength, $\lambda=2 \pi / k$, where $\omega$ is wave angular frequency and $k$ is wavenumber, are related according to the dispersion relation:

$\omega^{2}=\left(g k+\frac{\sigma k^{3}}{\rho}\right) \tanh (k d)$

where $g$ is local gravitational acceleration, $\rho$ is fluid density, $\sigma$ is surface tension, and $d$ is fluid depth. In the case of deep water waves $(d>0.5 \lambda)$, the $\tanh (k d)$ factor approaches unity, so that the deep water wave speed, $c_{0}$, is given as:

$c_{o}=\sqrt{\frac{g}{k}+\frac{\sigma k}{\rho}}$

Using $d=1 \mathrm{~m}, \rho=1000 \mathrm{~kg} / \mathrm{m}^{3}$ and $\sigma=7.2 \times 10^{-2} \mathrm{~N} / \mathrm{m}$, the wavelength dependence of the wave speed is shown in Fig. 1. For this case, there is a minimum wave speed at a wavelength of $1.73 \mathrm{~cm}$. From this minimum, gravity waves move faster with increasing wavelength, and capillary waves move faster with decreasing wavelength.

The presence of an oil film does not completely alter the mechanisms of wind wave generation, but does change the energy input and rate of amplitude dissipation. The reduction in surface tension increases the critical wind speed needed for wind wave generation (Kawai 1979). This means that it takes a faster wind to deform the now "smoother" surface and the oil film inhibits the growth of waves at wind speeds below this critical value. Additionally, the presence of oil leads to an increased rate of energy dissipation in capillary 


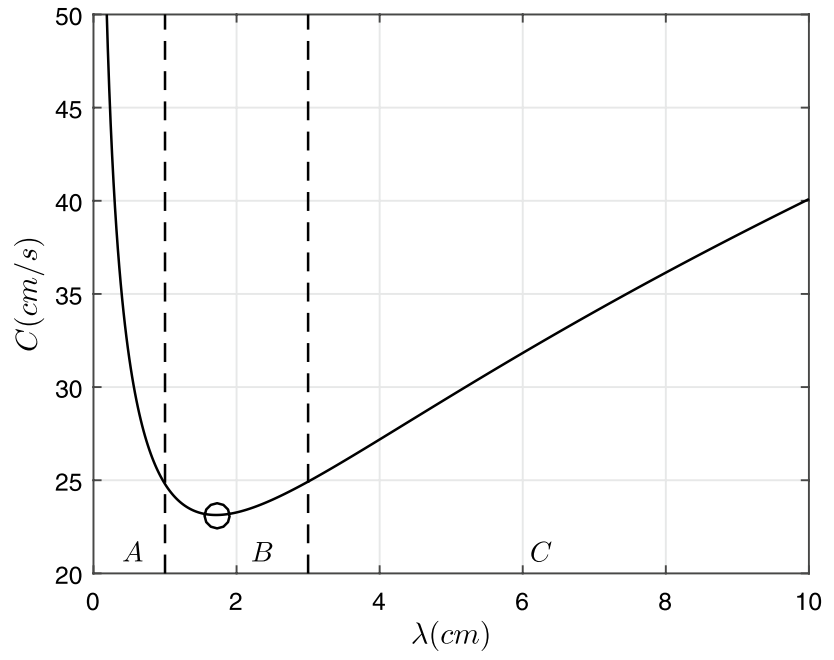

Fig. 1 The complete dispersion relation for surface water waves. Regions A, B, and C refer to the capillary, gravity-capillary, and gravity wave regimes, respectively. Here, the capillary wave regime is defined as surface tension contributing $>75 \%$ of the restoring force, and the gravity wave regime as surface tension contributing $<25 \%$ of the restoring force. The minimum phase speed (O) occurs at a wavelength of $1.73 \mathrm{~cm}$

waves due to a phenomenon known as the Gibbs-Marangoni effect (Behroozi et al. 2007; Lucassen-Reynders and Lucassen 1970). This results in an enhanced attenuation of capillary waves and therefore a shift in the most unstable wavenumber to smaller wavenumbers. This shift means a developing wind wave field is dominated by waves with longer wavelengths and diminished growth rates (Creamer and Wright 1992).

\section{Experimental Method}

\section{Laboratory}

Wind waves were generated in an open top rectangular Plexiglas tank $(50 \times 10 \times 38 \mathrm{~cm})$ attached at one end to a wind tunnel $(50.5 \times 10 \times 15 \mathrm{~cm})$ fitted with four flow straighteners
(Fig. 2). The fan produced wind velocities of $\approx 6 \mathrm{~m} / \mathrm{s}$, and the long sides of the trough were raised so that a more uniform wind field could be generated across the water surface. As a result of the wind, a current moving down the tank at $3 \mathrm{~cm} / \mathrm{s}$ was observed. The tank was filled with $19 \mathrm{~L}$ of tap water and dyed with rhodamine. A small inflow of water, used to give a continuous overflow, reduced wave reflections and prevented the buildup of oil at the downwind end of the tank.

A $40 \mathrm{~mW}(532 \mathrm{~nm})$ green laser with line-generating optics was mounted above the tank to illuminate the water surface, and wave characteristics were measured in the dark by recording the vertical oscillation of the laser light sheet with a Panasonic GH4 camera running at 90 fps mounted in front of the tank. The camera was mounted so that each pixel along the laser light sheet was a constant $0.0273 \mathrm{~cm} /$ pixel. The pixel location of the recorded interface was found by identifying the center of mass of light intensity of each column of pixels (1920 columns). The extracted interface was then smoothed and gaps, artifacts of the light sheet disappearing in waves, were filled by fitting a polynomial of varying degree. Any remaining noise from the extracted interface, such as tank scale oscillations, were removed with filtering techniques (MATLAB 2015).

To observe the effect of oil on the wind waves, an oil film was created by injecting extra virgin olive oil (Triolein) from a syringe onto the water's surface at the upwind end of the tank. This was done after achieving a fully developed wind wave field on a clean water surface. Approximately $5 \mathrm{~cm}^{3}$ of oil was injected over $10 \mathrm{~s}$, and dispersed across the water surface by the wind.

\section{Field}

To compare wind wave generation in BML in the presence and absence of oil, a section of the water surface was isolated to reduce the hydrocarbon concentration. A rectangular oil boom $(4.5 \times 6 \mathrm{~m})$, anchored in 4 locations, was deployed around a fixed instrument post (Figs. 3 and 4). The boom arms were constructed with commercially available foam rods, $7 \mathrm{~cm}$ in diameter, and fitted with a weighted plastic
Fig. 2 Diagram of the laboratory setup

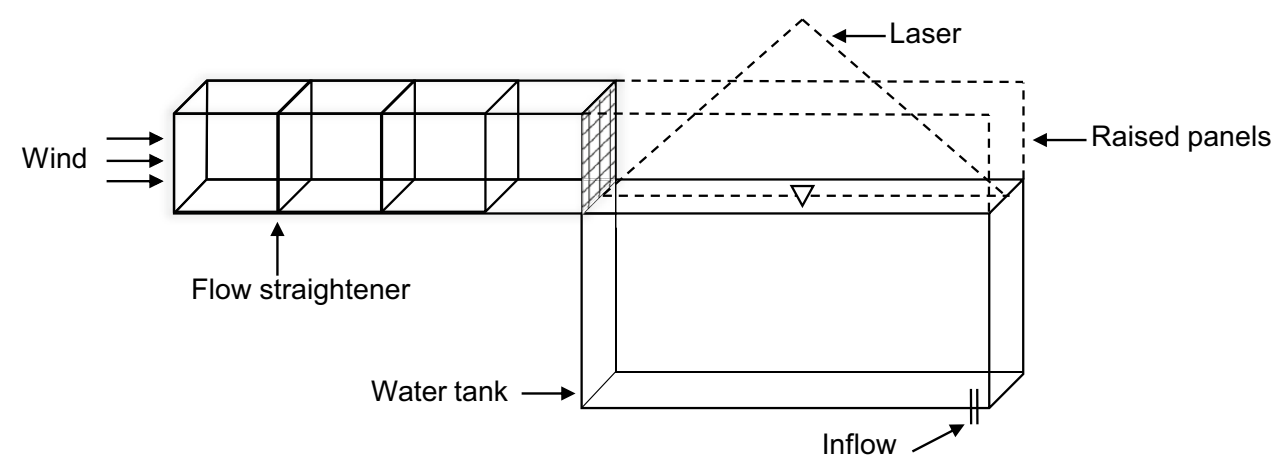




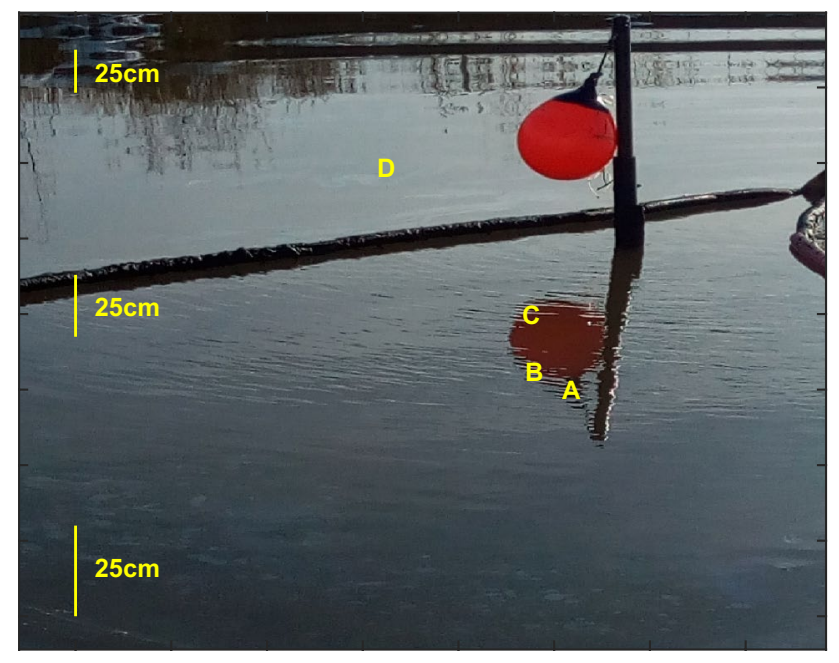

Fig. 3 Digital image of the oil boom with analyzed points in the boom $(\mathrm{A}-\mathrm{C})$ and outside the boom (D). The wind is from the top right to bottom left and tree reflections are present in the top of the image

skirt that hung $45 \mathrm{~cm}$ into the water. During a period when the water surface was relatively hydrocarbon free, the boom was deployed and left for three weeks. The fetch inside the boom was large enough so that capillary and gravity-capillary waves, both affected by oil, could be generated by the wind. Short waves generated outside the boom were blocked by the boom arms, but longer waves were able to propagate inside.

At intermittent periods throughout the boom deployment, images of the water inside and outside the boom were captured with an 8 megapixel digital camera. Since wave crests and troughs appear as different image light intensities, the wavelengths could be determined by differences in light reflection. It was found that analyzing the waves inside the boom near the edge of the reflection of a red mooring buoy gave the best contrast and provided more confidence as to the location of the crests and troughs (Fig. 3). Additionally, in the images, the pixel resolution goes from fine to coarse moving away from the foreground. To correct for this distortion, objects of known length in the foreground and background were chosen and their pixel to length ratios were determined. A pixel to length ratio for each row and column was then assigned by linear interpolation. Each location of the analyzed wave field was chosen far enough away from the boom and instrument station so that wave interference was minimized. The wind speed and direction during the boom deployment were recorded and the amount of oil present inside and outside the boom was visually noted in the images.

\section{Results}

\section{Laboratory}

Visualization of the effect of oil on wind waves generated in the wave flume is shown in a time-space plot (Fig. 5a). This figure represents a compilation of interface heights observed in 2500 images collected over $28 \mathrm{~s}$ (only the middle $15 \mathrm{~s}$ is shown). During the experiment, the wave field underwent four obvious changes in wave characteristics indicated by regions A-D. Initially, before the fan was turned on, the water surface was free of oil and waves (A). Then, after the

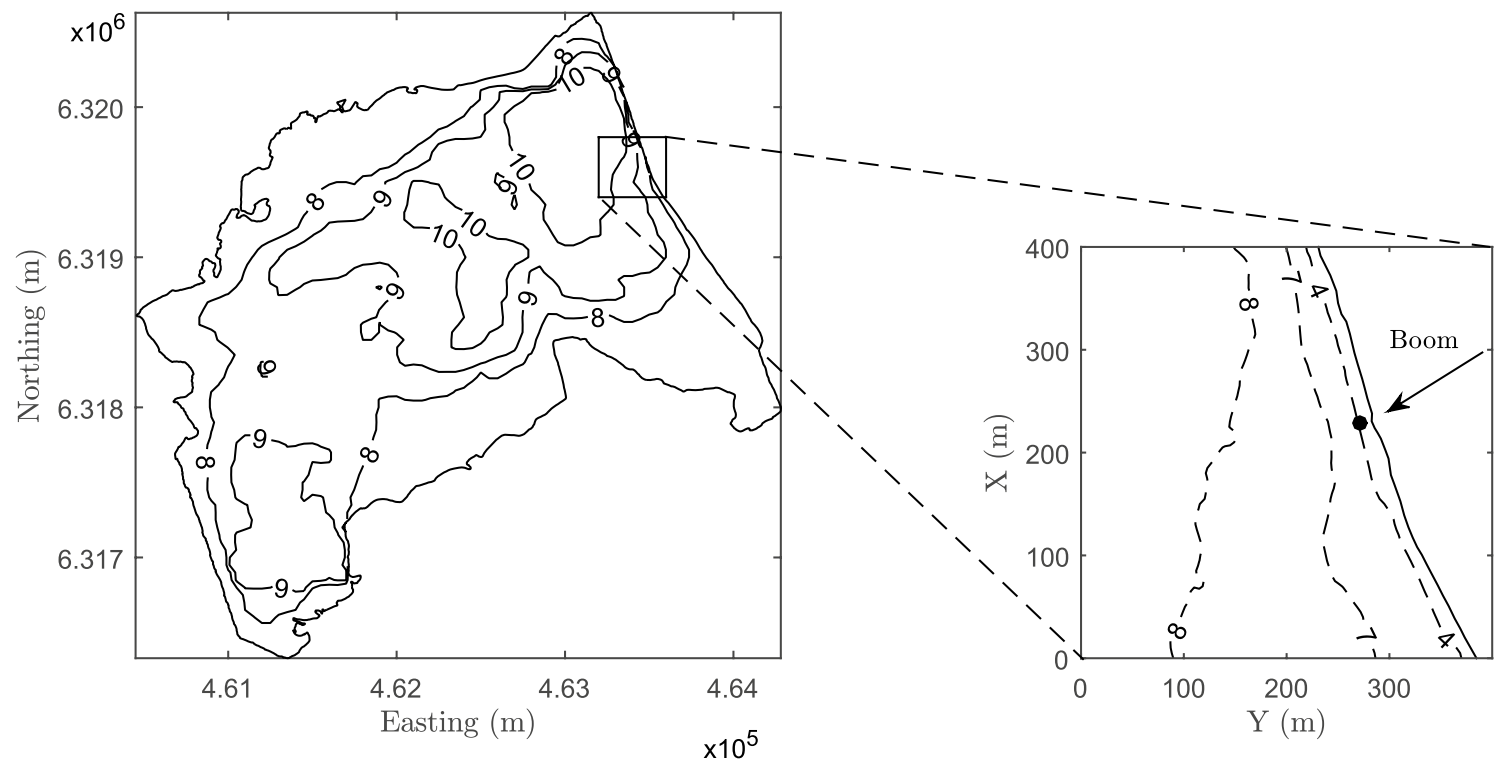

Fig. 4 Plan view of Base Mine Lake with depths in meters indicated. The inset shows the location of the oil boom and the black pole (black dot) 
Fig. 5 a Plot of the deviation of the surface elevation from along the tank with increasing time. The wave characteristics for the (A) calm surface, (B) developing wind wave field, $(\mathrm{C})$ fully developed wind wave field, and (D) wind wave field in the presence of olive oil applied at $x=0 \mathrm{~cm}$ and $t=16 \mathrm{~s}$, are shown. Shading represents the wave amplitude with white indicating a crest and black indicating a trough. b Wave amplitude with time at $\mathrm{x}=25 \mathrm{~cm}(-)(\mathrm{A}-\mathrm{D}, \mathbf{a})$
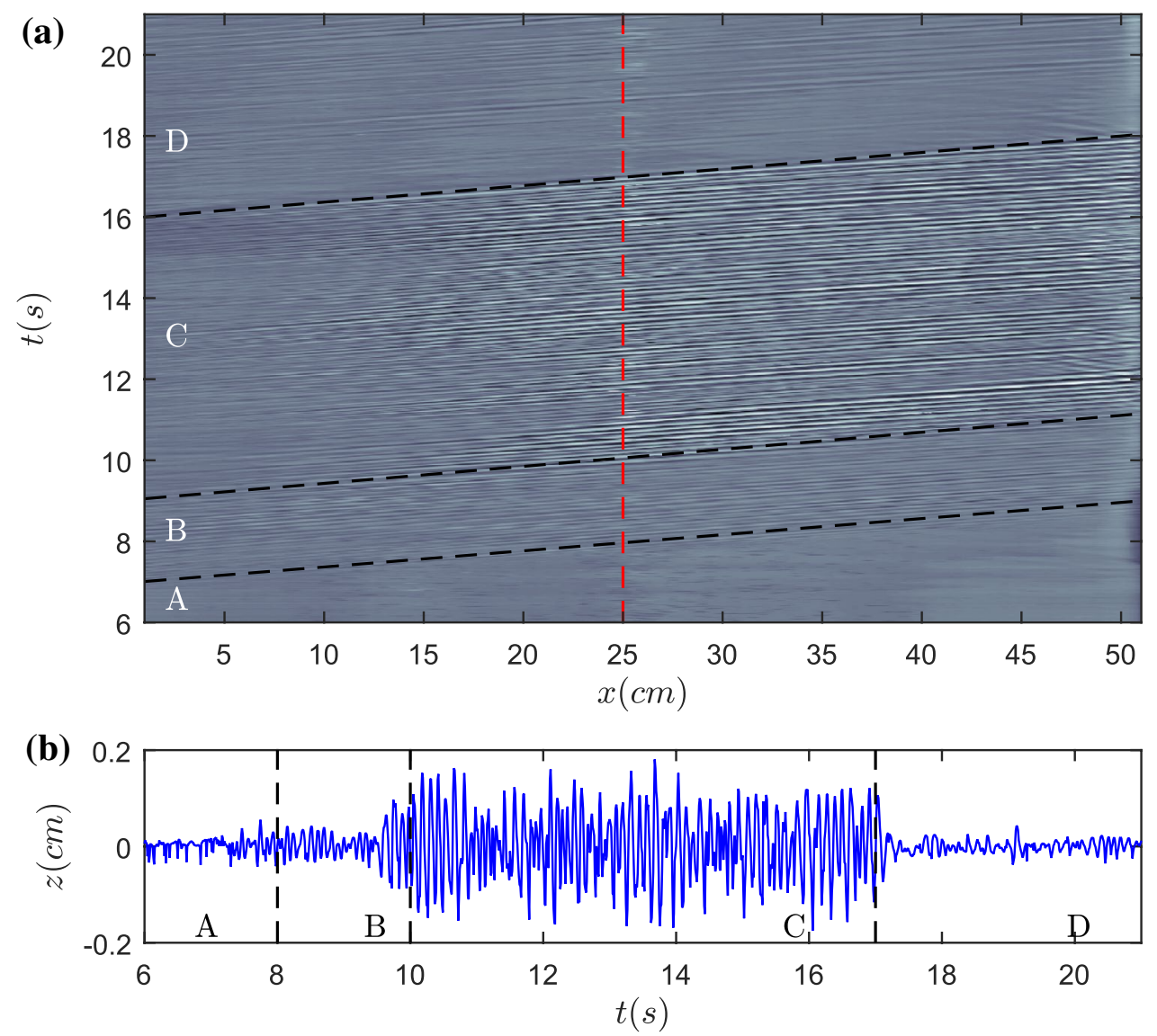

fan was started, a developing wind wave field - a wave field that was not yet fetch limited-was observed (B). Since the wind did not impact the water surface for the first $5 \mathrm{~cm}$, and wave reflections were present in the last $5 \mathrm{~cm}$, results in these regions were ignored. In a short time, the developing wind wave field transitioned into a fully developed wind wave field and waves propagated with fairly uniform wave speed, wavelength, and amplitude (C). Lastly, oil was applied to the water surface and immediately the amplitude of the waves decreased at the windward end of the tank (D). After a few seconds, the oil spread downwind and the entire wind wave field was damped out.

To better understand the change in wave amplitude during the experiment, a time transect at the center of the tank is shown (Fig. 5b). Notice the growth of the developing wind waves (B), and that the fully developed wind wave field (C) contains wave packets, a consequence of the dispersion relation. After the addition of oil, the wave amplitudes resemble those in the early stages of a developing wind wave field (D). This is illustrated by the immediate reduction in amplitude from $\pm 0.15 \mathrm{~cm}$ in (C) to $\pm 0.03 \mathrm{~cm}$ in (D).

To gain further insight into the physical mechanisms at work, 2D wave spectra were computed using the fast Fourier transform (FFT) function in MATLAB (2015). The 2D FFT allows characterization of the wave spectra simultaneously in wave number and frequency space (Wang and Hwang 2004; Weinfurtner et al. 2013). Comparing Fig. 6a for the clean surface to Fig. $6 \mathrm{~b}$ with an oil film, it is clear that the oil film dampens high frequency waves. This is shown as a reduction in spectral energy above $10 \mathrm{~Hz}$ and elimination above $20 \mathrm{~Hz}$. In addition, noting that wave energy is proportional to wave amplitude squared, the oil had the effect of diminishing wave amplitudes at all wave numbers. Figure $6 \mathrm{a}$ and $\mathrm{b}$ show the theoretical dispersion relationship on a clean and oil-contaminated surface with a $3 \mathrm{~cm} / \mathrm{s}$ wind generated flow.

At each wavenumber in Fig. 6a and b, the energy was summed over $\omega$ and plotted as a function of wavenumber (Fig. 6c). It is clear that all wavenumbers are much less energetic in the presence of an oil film. It is also apparent that the peak in the spectrum is shifted from 36 cycles $/ \mathrm{m}$ $(\lambda=2.8 \mathrm{~cm})$ on a clean water surface to 27 cycles $/ \mathrm{m}$ $(\lambda=3.7 \mathrm{~cm})$ on an oil-contaminated surface. This shift is statistically significant at the $95 \%$ confidence level and is qualitatively similar to the shift shown in the linear instability analysis of Creamer and Wright (1992). It is worth noting that the energy in the longest waves is not the same regardless of the surface contamination, since oil has little effect on long waves. However, as the waves generated in the experiment never exceeded a wavelength of $6 \mathrm{~cm}$, it is 

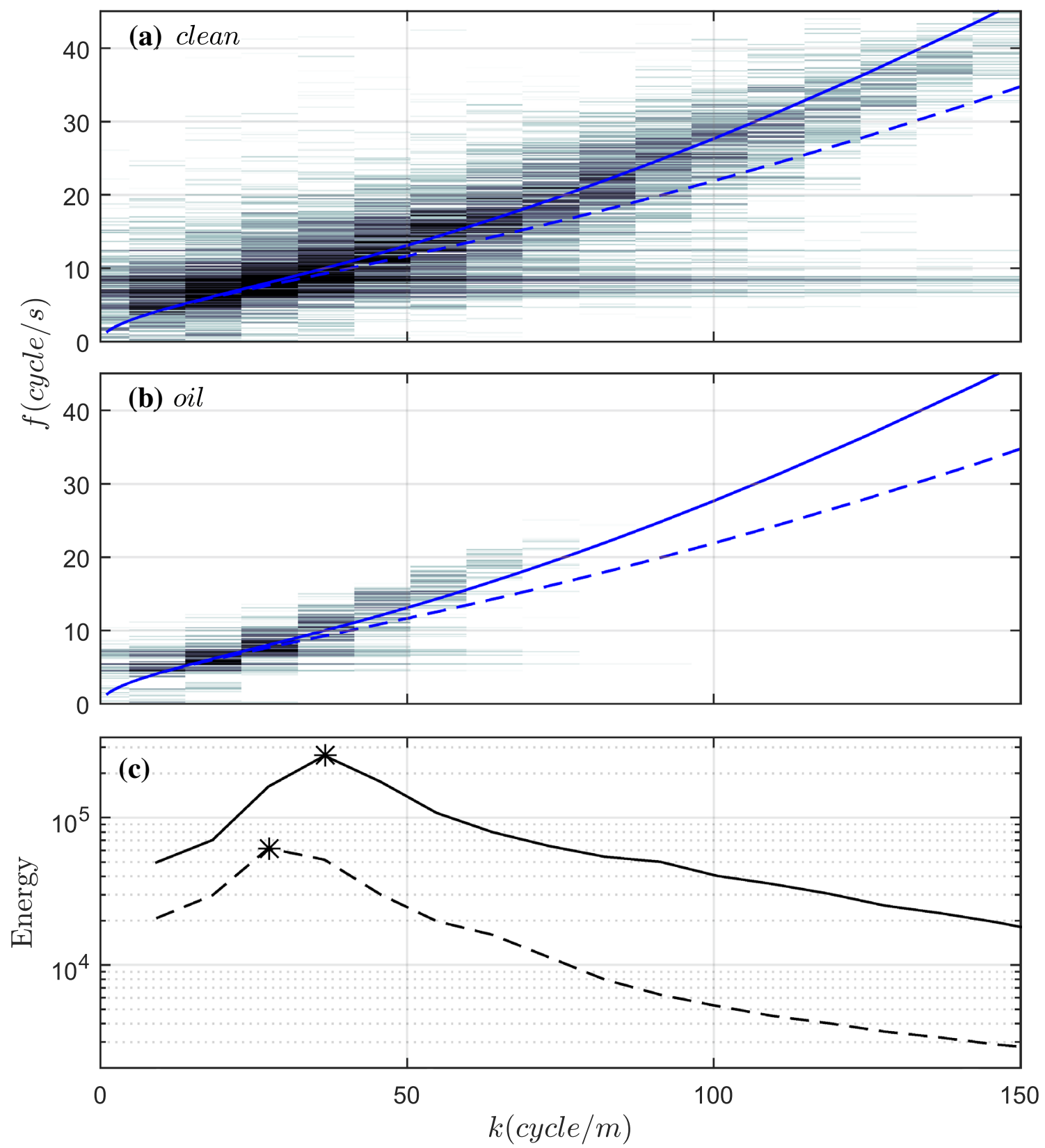

Fig. 6 Spectral analysis of the laboratory generated waves on a the clean surface $(25-40 \mathrm{~cm}$ and $11-15 \mathrm{~s}$ from region $\mathrm{C}$, Fig. 5) and b the oil contaminated surface $(25-40 \mathrm{~cm}$ and $17-21 \mathrm{~s}$ from region $\mathrm{D}$, Fig. 5). Dark colors denote high energy. The dispersion relations (3.1)

not surprising that even the longest waves were still slightly affected by the oil film. If the experiment were extended to smaller wavenumbers (longer wavelengths), it is likely that these energies would become equal.

\section{Field}

The wind wave characteristics at three locations inside the boom $(\mathrm{A}-\mathrm{C})$ and one location outside the boom (D) were using the surface tension of water (-) and olive oil (-) are overlaid. In $\mathbf{c}$ the energy at each wavenumber for water (-) and oil (-) surface along with the peak of the spectrum $(*)$ are shown. Note that $f=\omega / 2 \pi$

captured (Fig. 3). Qualitatively, there were more small ripples inside the boom (A-C) than there were outside (D). The wind at this time was blowing from the background to the foreground of the image and so the waves seen at A-C were also propagating in this direction. At the downwind end of the boom, the image foreground, there was an oil film inside the boom, but not at A-C (Fig. 3). This film can also be seen at location D. Looking at a plot of A-D showing normalized light intensity, it is clear that there are waves inside the 
boom, but none outside (Fig. 7). This matches our visual interpretation of Fig. 3, and indicates a dampening of the wave field in the presence of an oil film.

To get an idea of the wavelengths present at A-D, vertical transects in y of each plot in Fig. 7 are shown in Fig. 8. Inside the boom, the waves exhibit wavelengths ranging from 1.0 to $1.4 \mathrm{~cm}$ (Fig. 8a-c), which falls to the left of the minimum in the dispersion relation, indicating that the waves are governed primarily by surface tension. Outside the boom, there are no discernible waves (Figs. $7 \mathrm{~d}$ and $8 \mathrm{~d}$ ).

\section{Conclusions}

The results of laboratory and field experiments revealed a dramatic change in the observed wind wave field in the presence of an oil film. It was observed that the addition of an oil film onto an already fully developed wind wave field acted to dampen capillary waves, suggesting that the growth of the wind wave field was slower than it would otherwise have been without an oil film. Additionally, it was postulated that the oil film acted to increase the critical wind speed needed for wind wave generation, as described by theory (Kawai 1979). Above this critical wind speed of about $5 \mathrm{~m} / \mathrm{s}$, the wave damping effect of a surface film diminishes rapidly (Fitzgerald 1963; Gottifredi and Jameson 1968; Alpers and Huhnerfuss 1989) and while $5 \mathrm{~m} / \mathrm{s}$ is relatively slow, the wind speed at the water surface in many mine pit lakes is significantly reduced by high surrounding walls (Stevens and Lawrence 1998). Hamblin et al. (1999) showed that this reduction in wind speed resulted in a decrease in mixing in the water cap. In conclusion, this means that a higher wind speed would be required to develop a similar wind wave field as would be found on a non-contaminated surface or a contaminated surface with low surrounding walls.

These results have important implications on mine pit lake water quality and management of reclamation efforts. Removal of an oil film may increase mixing in the water cap, which in turn could lead to increases in dissolved oxygen and turbidity and changes in the intensity and timing of water cap turnover. Alternatively, the presence (or addition) of an oil film may decrease mixing in the water cap and suppress water cap turnover, which may act to isolate near-bed containments. This suggests that pit lake reclamation efforts to remove oil films should include simultaneous monitoring of multiple water quality parameters to aid in assessing the impact on the physical and biological environment. Additionally, the timing of oil film removal relative to water cap stratification should be considered to avoid increases in turbidity and water cap turnover during biologically sensitive periods.

In summary, this work shows that an oil-contaminated surface leads to a wind wave field dominated by longer wavelength waves that take more time to develop and grow (a)
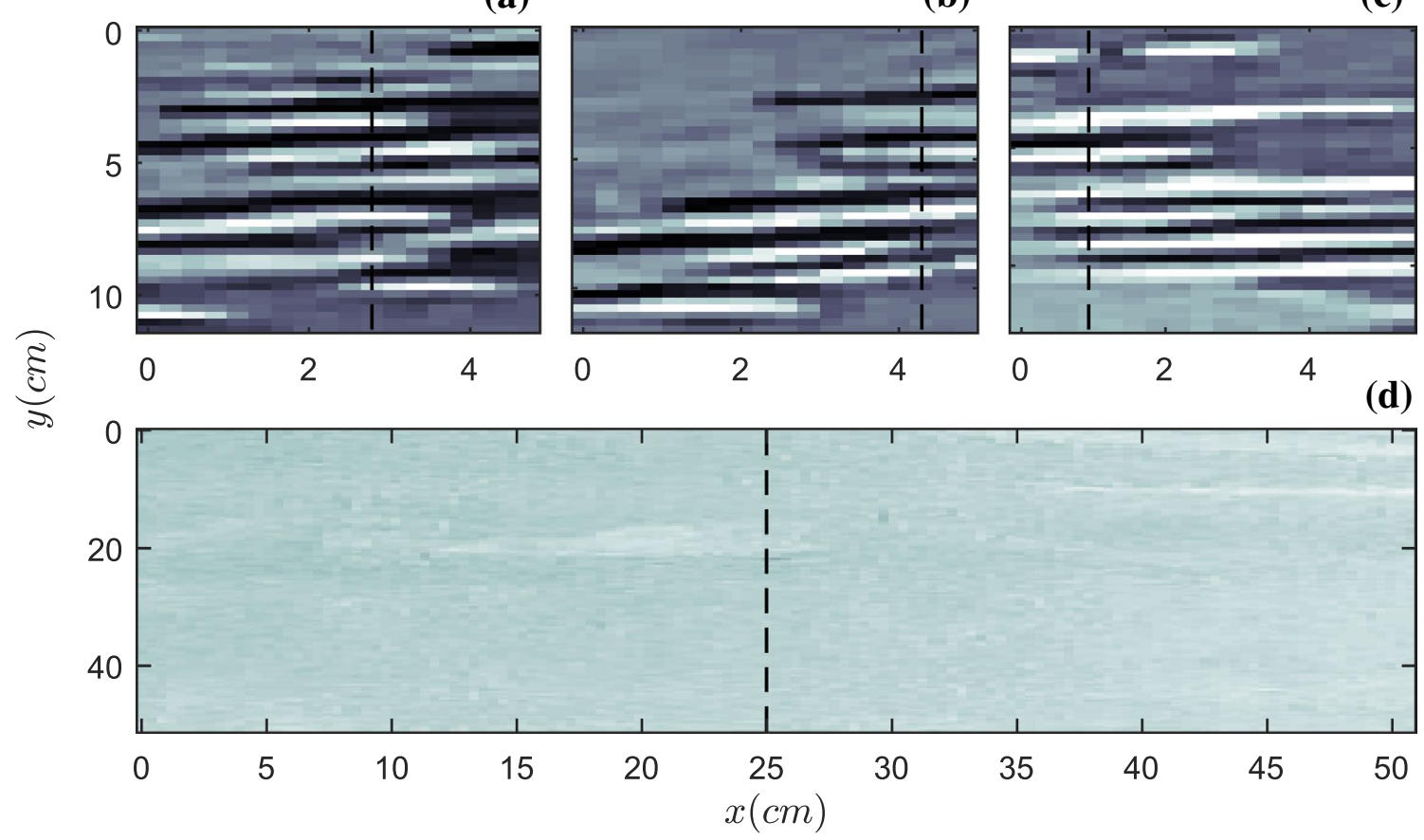

(c)
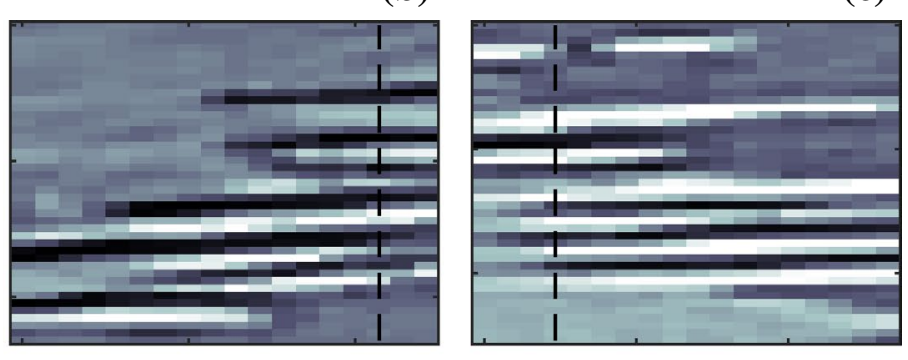

d)

Fig. 7 Plot of light intensity in regions a-d of Fig. 3. Dark colors represent the wave crests and light colors wave troughs. All plots are on the same color scale. Vertical transects in y (-) are shown in Fig. 8 


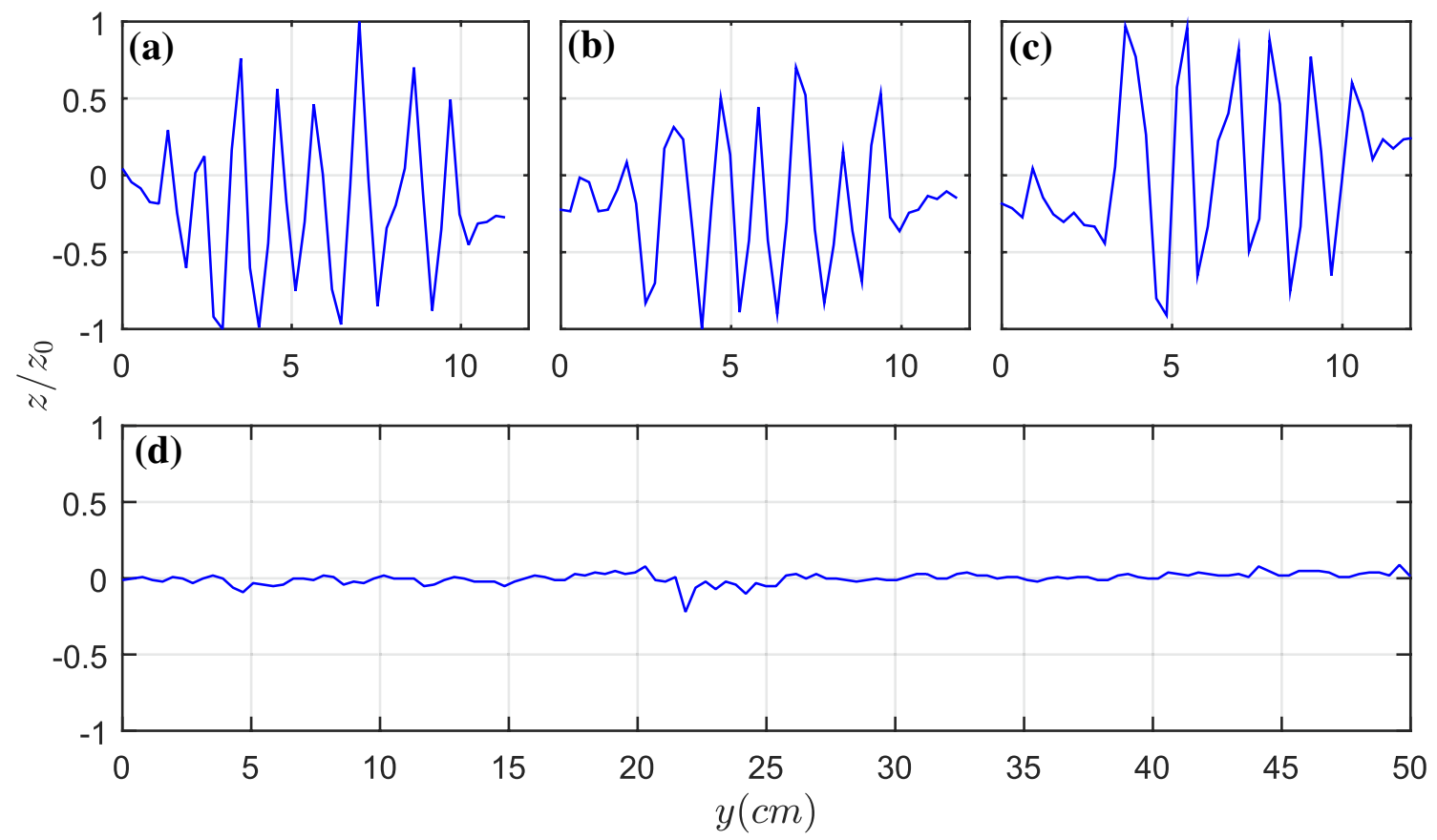

Fig. 8 Wavelength transects for Fig. 7 inside (a-c) and outside (d) the oil boom. Amplitude has been normalized by the maximum amplitude $\left(\mathrm{z}_{\mathrm{o}}\right)$ of transect $(\mathbf{a})$

at a slower rate. Since wind waves are direct drivers of the physical processes in a water body, it is postulated that the oil film on BML may be affecting the flux of momentum from the wind, lake circulation, and the fluxes of gas and heat. More specifically, a wind wave field that takes longer to develop and grow may lead to less mixing in the upper water column, which may in turn lead to a reduction in the concentration of suspended solids and dissolved oxygen. However, further research would be required to confirm this.

Acknowledgements This work was supported by a collaborative research agreement between Syncrude Canada Ltd. and the University of British Columbia. The authors are grateful for information and advice from Roger Pieters, laboratory work from Jared Zhang and Simon Fang, and field coordination and support from the employees of the Syncrude Reclamation and Closure Research Department.

Open Access This article is licensed under a Creative Commons Attribution 4.0 International License, which permits use, sharing, adaptation, distribution and reproduction in any medium or format, as long as you give appropriate credit to the original author(s) and the source, provide a link to the Creative Commons licence, and indicate if changes were made. The images or other third party material in this article are included in the article's Creative Commons licence, unless indicated otherwise in a credit line to the material. If material is not included in the article's Creative Commons licence and your intended use is not permitted by statutory regulation or exceeds the permitted use, you will need to obtain permission directly from the copyright holder. To view a copy of this licence, visit http://creativecommons.org/licenses/by/4.0/.

\section{References}

Aitken J (1884) 3. On the effect of oil on a stormy sea. Proc R Soc Edinb 12:56-75

Alpers W, Huhnerfuss H (1989) The damping of ocean waves by surface films: a new look at an old problem. J Geophys Res 94(C5):6251-6265

Arriaga D, Nelson TC, Risacher FF, Morris PK, Goad C, Slater GF, Warren LA (2019) The co-importance of physical mixing and biogeochemical consumption in controlling water cap oxygen levels in Base Mine Lake. Appl Geochem 111:104442

Behroozi P, Cordray K, Griffin W, Behroozi F (2007) The calming effect of oil on water. Am J Phys 75(5):407-414

Broecker HC, Petermann J, Wolfgang S (1978) Influence of wind on $\mathrm{CO}_{2}$-exchange in a wind-wave tunnel, including effects of monolayers. J Mar Res 36(4):595-610

Creamer DB, Wright JA (1992) Surface films and wind wave growth. J Geophys Res-Oceans 97(C4):5221-5229

Fitzgerald LM (1963) Wind-induced stresses on water surfaces: a wind-tunnel study. Aust J Phys 16:475-489

Franklin B, Brownrigg W, Farish M (1774) Of the stilling of waves by means of oil. Extracted from sundry letters between Benjamin Franklin, LL. DFRS William Brownrigg, MDFRS and the reverend Mr. Farish. Philosophical Transactions 64: 445-460

Fulford GD (1968) Pouring holy oil on troubled waters. Isis 59(2):198-199

Giles CH (1969) Franklin's teaspoonful of oil. Studies in the early history of surface chemistry, part 1 . Chemistry and Industry $1616-1624$

Gottifredi JC, Jameson GJ (1968) The suppression of wind-generated waves by a surface film. J Fluid Mech 32(3):609-618

Hamblin PF, Stevens CL, Lawrence GA (1999) Simulation of vertical transport in mining pit lake. J Hydraul Eng 125(10):1029-1038 
Kawai S (1979) Discussion on the critical wind speed for wind-wave generation on the basis of shear-flow instability theory. J Ocean Soc Jap 35(5):179-186

Kinsman B (1984) Wind waves, their generation and propagation on the ocean surface. Courier Corporation, Chelmsford

Lawrence GA, Ward PR, MacKinnon MD (1991) Wind-waveinduced suspension of mine tailings in disposal ponds-a case study. Can J Civ Eng 18(6):1047-1053

Lawrence GA, Tedford EW, Pieters R (2015) Suspended solids in an end pit lake: potential mixing mechanisms. Can J Civ Eng 43(3):211-217

Liu HT, Lin JT (1979) Effect of an oil slick on wind waves. Proc, Int Oil Spill Conf 1:665-674

Lucassen-Reynders EH, Lucassen J (1970) Properties of capillary waves. Adv Colloid Interfac 2(4):347-395

MATLAB (2015) The MathWorks. MATLAB, Natick

Pieters R, Lawrence GA (2009) Effect of salt exclusion from lake ice on seasonal circulation. Limnol Oceanogr 54(2):401-412

Pockels A (1891) Surface tension. Nature (London) 43:437-439

Reynolds O (1880) On the effect of oil in destroying waves on the surface of water. Brit A Adv Sci 50:409-425
Sparrow BC (1883) The use of oil in calming rough seas. Ann Rep US Life-Sav Serv 427(1):87

Stevens CL, Lawrence GA (1998) Stability and meromixis in a waterfilled mine pit. Limnol Oceanogr 43(5):946-954

Tedford E, Halferdahl G, Pieters R, Lawrence G (2019) Temporal variations in turbidity in an oil sands pit lake. Environ Fluid Mech 19(2):457-473

Wang DW, Hwang PA (2004) The dispersion relation of short wind waves from space-time wave measurements. J Atmos Ocean Tech 21(12)

Weinfurtner S, Tedford EW, Penrice MC, Unruh WG, Lawrence GA (2013) Classical aspects of Hawking radiation verified in analogue gravity experiment. In: Faccio D, Belgiorno F, Cacciatori S, Gorini V, Liberati S, Moschella U (eds) Analogue gravity phenomenology. Lecture notes in physics, vol 870. Springer, New York, pp 167-180

Yanful EK, Mian MH (2003) The nature and implications of resuspension in subaqueous sulfide tailings. Univ Alta. https://doi. org/10.7939/r3-vemn-jt51 